This is an electronic reprint of the original article. This reprint may differ from the original in pagination and typographic detail.

Author(s): Laihonen, Petteri; Szabó, Tamás Péter

Title: $\quad$ Studying the visual and material dimensions of education and learning

Year: $\quad 2018$

Version:

Please cite the original version:

Laihonen, P., \& Szabó, T. P. (2018). Studying the visual and material dimensions of education and learning. Linguistics and Education, 44, 1-3.

https://doi.org/10.1016/j.linged.2017.10.003

All material supplied via JYX is protected by copyright and other intellectual property rights, and duplication or sale of all or part of any of the repository collections is not permitted, except that material may be duplicated by you for your research use or educational purposes in electronic or print form. You must obtain permission for any other use. Electronic or print copies may not be offered, whether for sale or otherwise to anyone who is not an authorised user. 
Laihonen, P. \& T. P. Szabó 2017. Studying the visual and material dimensions of education and learning. Linguistics and Education. https://doi.org/10.1016/j.linged.2017.10.003

Editorial to a Special Issue

\section{Studying the visual and material dimensions of education and learning}

In this special issue we offer an extensive exploration and conceptualization of the visual and material dimensions of education and learning, bringing together a cluster of emerging scholarly ventures that investigate how people create, explore, interpret, negotiate, adjust, contest, transform and envision learning environments. This edited collection of research papers shows the versatility of the growing field of schoolscape studies and the high potential of recent theoretical and methodological innovations to investigate the visual and material dimensions of education and learning. The studies share the view that premises designed for education as well as other spaces can equally serve as sites of teaching and learning. Among others, the papers ask what the environment offers and how images, multimodal texts and artifacts can be used to enhance (language) learning and communication. The empirical case studies apply a wide range of theoretical and methodological approaches, bringing innovation into the generation, presentation and analysis of data from varying educational institutions and mundane settings covering geographical sites from Europe and North America.

In a previous chapter to a volume 'Researching Multilingualism' (Laihonen \& Szabó 2017), we provided an overview of approaches to the study of linguistic landscapes (e.g. Shohamy \& Gorter 2009; Shohamy 2012; Gorter in this SI) and semiotic practices in educational environments, taking account of both theory and method. In our present introduction, we discuss recent developments in the field, which are then exemplified and elaborated in detail in the articles of this Special Issue.

In two volumes, Discourses in place (2003) and Nexus Analysis (2004), Scollon and Wong Scollon employed two terms - visual semiotics and geosemiotics - to capture the increasing shift towards visual communication in contemporary social life. Their work built on and extended the tradition of critical discourse analysis. They argued that the study of visual semiotics represents a turn "from spoken, face-to-face discourses to the representations of that interaction order in images and signs" (2003: 82). Working in the realm of educational anthropology, Brown was the first to propose the term schoolscape, which "comprises the physical and social setting in which teaching and learning take place" (Brown 2005: 79). We have considered the investigation of schoolscapes to be relevant to research into the visual socialization of children, into the ways in which they are oriented to visual literacy and into the visual literacy practices of both peers and adults. That is, we view visual literacy not only as the ability to interpret visual signs, but also as a social practice - one in which teachers, students, parents, administrators and other actors exercise agency while engaging in visual communication. We also argue that language ideologies can be reflected in and constructed through schoolscapes. That is, similarly to classroom interaction and other educational practices, schoolscapes can be interpreted as displays or materializations of the 'hidden curriculum' regarding language values (cf. Johnson 1980). Finally, work on the linguistic landscapes of schools extends the critical and ethnographic strand of research on multilingualism and heteroglossia since it expands the field by taking in a broader range of resources for meaning making (e.g. Martin-Jones, Blackledge \& Creese 2012). 
From a language ecology approach (e.g. van Lier 2004), schoolscape studies and educational development projects have established connections between visual literacy practices inside and outside the classroom. For example, students participating in the project 'Språkskap Swedish as a Social Language' (Clark \& Lindemalm 2011) discussed interactional practices that they had explored in the 'wild' (that is, outside the classroom). Linking urban visual literacy practices and classroom discussions has also been in the center of several projects (e.g. Sayer 2010; Chiou-lan \& Dooley 2014) that have raised students' awareness to the changing semiotics of multilingualism. Such projects have conceptualized place as a social construct and have blurred boundaries between the 'inside' world of a classroom and the 'outside' world, for example interpreting the whole world as a classroom (Malinowski 2015). Unavoidably, a focus on the creative language practices and combination of semiotic resources in multilingual meaning-making has led to the deconstruction of language barriers and the promotion of translanguaging pedagogies (cf. Gorter \& Cenoz 2015).

Research into schoolscapes has been characterised by the same rich diversity as the broader field of linguistic landscape research, and has generated similar methodological debates. Among others, the status and methods of quantitative methods have been changed since the late 1990s when such methods were in the centre of linguistic landscape-oriented social inquiry. Further, a well-established tradition of ethnographic research on the organisation of visual and material culture in local schoolscapes has incorporated a large variety of methods and data types. Traditional 2D images and pen and pencil or print products are now combined with and at times replaced by digital media, which according to Blommaert (2015), has brought the most significant change in communication and diversity of the new millennium. Further, recent schoolscape studies have involved research participants (teachers, students, school administrators, parents, etc.) to uncover the language ideologies and discourses underpinning sign use and production. Inclusive research agendas (e.g. Nind 2014) reposition research participants as co-producers of knowledge (e.g. Facer \& Enright 2016). Participants are labelled in various ways that implicate equal partnership such as $\mathrm{CO}^{-}$ researchers and participant-researchers (Nind 2014). In best contemporary research practices, participants have become influential at various points of the research process, from initial negotiations of cooperation through data generation to analysis and dissemination.

Since ethnographic research involves extended observation over time, return visits to the field enable the researcher to capture changes as well. Consider, for example, changes triggered by the introduction of a new national or regional language policy (see Brown's article in this issue for an example), or by new patterns of transnational migration. Multi-sited ethnography, involving the comparison of schoolscapes across different schools has also proved to be a fruitful approach, albeit more demanding in terms of time.

As the scope of research in multilingual schools and classrooms has been broadened to incorporate schoolscapes and different visual and semiotic practices, researchers have also begun to build a visual dimension into their own research practice. Visual methods such as photography or the use of drawings have been employed in research in multilingual settings, at the stage of data generation and also at the stages of data interpretation and analysis. The visual turn in research on multilingualism has focused on the one hand on out-of-school contexts and on the other hand on language teaching and learning in school and to the raising of language awareness among students. Newest methods apply different digital technologies and applications such as video-editing, augmented reality gaming or virtual simulation (e.g. Malinowski 2016; Hellermann, Thorne \& Fodor 2017). 
The present special issue is the first systematic collection of studies that deal with educational policies and practices from a linguistic landscape point of view (see also Gorter's commentary in this issue). As first ventures into a specific theoretical concept, methodology or theme, the chosen empirical case studies advance numerous fields of applied linguistic inquiry.

The first three papers concentrate on school premises and provide qualitative analysis of fieldwork data from an ethnography-oriented approach. Pakarinen and Björklund investigate immersion students' view on their linguistic identity in a dual-language setting, showing how several languages in the schoolscape contribute to the construction of multilingual identities. This exploratory study highlights the interplay between languages in school signage and students' language practices, with a special emphasis on how schoolscapes may inflect immersion students' language use and shape their linguistic identities. The study finds that although the students' L1 (Finnish) and L2 (Swedish) are dominant in the schoolscape and thus construct visual bilingualism, the students mainly associate their multilingualism with bi- and multilingual discourses outside the school. Brown has developed diachronic analysis as a method to advance qualitative approaches to understand and compare schoolscapes across eras. She incorporates findings from a diachronic study of photos and teacher interviews in southeastern Estonian schools in 2001-2003 and 2013-2014 to appreciate and analyze dynamic forces changing schoolscapes. Her study concludes that the use of local languages has increased over time even though enduring norms about the primary role of the official language in schools has worked to maintain schoolscapes in Estonian. Brown contextualizes her findings in wider economic and cultural systems, with a special regard to the increasing impact of pre-primary education on pedagogical choices. Jakonen incorporates interactional research methodology into schoolscape studies and thus paves the road for the further methodological development of the field. He focuses on social action within the bilingual classroom, exploring how participants visibly orient to the surrounding material environment during instructional interaction. The data consist of video-recorded lessons from secondary-level education. His multimodal conversation analytic investigation focuses on interactions during which participants attend to classroom texts and semiotic objects. Sequential analyses of selected data show the occasioned nature of classroom objects and some ways in which instructional practices both draw on and modify the already existing visual and textual environment.

Savela provides a meta-analysis and a critique of established quantitative methods in linguistic landscape studies on education. In his analysis of classroom environments, Savela seeks to rehabilitate the quantitative by re-theorizing the landscape in linguistic landscape (LL), moving from an area based study of visible forms to a post-structuralist and (post)empiricist concept of landscape. He discusses previous quantitative LL research and introduces his own multidimensional quantitative approach. He argues that quantitative methods can provide valuable insight to the ordering of reality, its spatial differentiation and its patterns but cannot provide an in-depth understanding of the analyzed items due to the inherently reductive nature of classification.

The following two articles extend schoolscape studies towards out-of-school environments, and provide novel frameworks to establish connections between them. Zheng and her colleagues take a socio-cognitive comparative approach to the study of in-school and out-ofschool contexts in different geographic and social sites and offer a reconceptualization of space in learning. They look at language learners' experiential engagement with place with the support of mobile technologies. They propose a new language learning model that 
conceptualizes language learning as languaging with place as a 3D holographic experience, through which knowing co-arises with design, place-taking experiences with others, and mobile game narrative. Their analysis reveals how 3D human experiencing is extended by mobile technologies in learning situations. Przymus and Kohler investigate the linguistic landscape perceived in the vicinity of the school and its impact on education in bilingual settings. They introduce their own methodological framework coined Semiotic Index of Gains in Nature and Society (SIGNS) that investigates (1) diachronic and synchronic perspectives of place, (2) messages on syntagmatic and paradigmatic axes, (3) elective vs. circumstantial reverse indexicality, (4) societal myths, and (5) messages as metonyms/metaphors. Then the authors analyze 30 school neighborhoods in an American Southwest border town and find that wealthier neighborhoods are more likely to have linguistic landscapes indexed by Spanish than English, and these neighborhoods are subsequently more likely to support bilingual education. The paper demonstrates how semiotics, bilingual education, and the linguistic landscape together help us to understand better how and why linguistic landscapes are covertly influential.

Stepping beyond the spoken-written language bias in linguistic landscape studies, the final contribution by Tapio analyzes how the use of sign languages (re)configures educational spaces. Applying a Mediated Discourse Analysis approach, the paper focuses on the way signing students organize themselves spatially in social interaction in a university lecture hall. Tapio sees space as a concrete location and a social construct; also as normative actor with historical trajectories. From a methodological point of view, the author demonstrates how multimodal interaction analysis helps us in understanding the role architectural specifications pose some restrictions for visual-embodied interactions, and how participants (re)configure the space to some extend through explicit and implicit negotiation to adjust it to their needs.

Our Special Issue is concluded by Gorter's review of the above mentioned contributions. On the basis of his pioneering experience on both educational linguistics and linguistic landscape research, Gorter summarizes new trends emerging from the most recent literature of linguistic landscape, with a special regard to the contribution of this special issue to the investigation of the visual and material dimensions of education and learning. The review places the present special issue into a wider academic context, critically evaluates the developments, and articulates recommendations for future research.

\section{References}

Blommaert, J. 2015. Commentary: Superdiversity old and new. Language and Communication 44 (1), 82-89.

Brown, K. D. 2005. Estonian Schoolscapes and the Marginalization of Regional Identity in Education. European Education 37 (3), 78-89.

Chiou-lan, C. \& K. Dooley 2014. Learning English by walking down the street. ELT Journal 68: 113-123.

Clark, B. \& K. Lindemalm (eds.) 2011. Språkskap - Swedish as a Social Language. Stockholm: Ergonomidesign, Folkuniversitetet and Interactive Institute.

Facer, K. \& Enright, B. (2016). Creating Living Knowledge. Bristol: University of Bristol/AHRC Connected Communities.

Gorter, D. \& J. Cenoz 2015. Translanguaging and linguistic landscapes. Linguistic Landscape 1 (1-2), 54-74.

Hellermann, J., S. L. Thorne \& P. Fodor 2017. Mobile reading as social and embodied practice. Classroom Discourse 8 (2), 99-121. 
Johnson, N. B. 1980. The Material Culture of Public School Classroom: The Symbolic Integration of Local Schools and National Culture. Anthropology \& Education Quarterly, 11 (3), 173-190.

Laihonen, P. \& T. P. Szabó 2017. Investigating visual practices in educational settings: schoolscapes, language ideologies and organizational cultures. In M. Martin-Jones \& D. Martin (eds.), Researching multilingualism: Critical and ethnographic approaches, pp. 121-138. London: Routledge.

Malinowski, D. 2015. Opening spaces of learning in the linguistic landscape. Linguistic Landscape 1 (1-2), 95-113.

Malinowski, D. 2016. Learning to Translate Linguistic Landscape. Paper presented at LAUD Symposium (Landau, Germany) on 6 April.

Martin-Jones, M., A. Blackledge \& A. Creese (eds.) 2012. The Routledge Handbook of Multilingualism. London: Routledge

Nind, M. 2014. What is Inclusive Research? London: Bloomsbury.

Sayer, P. 2010. Using the linguistic landscape as a pedagogical resource. ELT Journal 64: 143-154.

Scollon, R. \& S. Wong Scollon 2003. Discourses in Place. London: Routledge.

Scollon, R. \& S. Wong Scollon 2004. Nexus Analysis: Discourse and the Emerging Internet. London: Routledge.

Shohamy, E. \& D. Gorter (eds.) 2009. Linguistic Landscape: Expanding the Scenery. London: Routledge.

Shohamy, E. 2012. Linguistic landscape and multilingualism. In M. Martin-Jones, A. Blackledge \& A. Creese (eds.), The Routledge Handbook of Multilingualism. London: Routledge, 538-551.

van Lier, L 2004. The Ecology and Semiotics of Language Learning: A Sociocultural Perspective. Boston: Kluwer Academic.

\section{Acknowledgements}

Laihonen's research is funded by the Academy of Finland; grant number: 299133.

Szabó's research is supported by the Society of Swedish Literature in Finland. 